Canadian

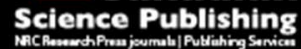

Canadian Journal of Microbiology Revue canadienne de de microbiologie

\title{
A survey of the antimicrobial susceptibility of Escherichia coli isolated from Sable Island horses
}

\begin{tabular}{|r|l|}
\hline Journal: & Canadian Journal of Microbiology \\
\hline Manuscript ID & cjm-2016-0504.R1 \\
\hline Manuscript Type: & Note \\
\hline Date Submitted by the Author: & 07-Oct-2016 \\
\hline Complete List of Authors: & $\begin{array}{l}\text { Timonin, Mary E.; Western College of Veterinary Medicine, Veterinary } \\
\text { Microbiology } \\
\text { Poissant, Jocelyn; University of Exeter College of Life and Environmental } \\
\text { Sciences } \\
\text { McLoughlin, Philip D.; University of Saskatchewan College of Arts and } \\
\text { Science, Biology } \\
\text { Hedlin, Cherise E.; University of Saskatchewan, Veterinary Microbiology } \\
\text { Rubin, Joseph E.; Western College of Veterinary Medicine, Veterinary } \\
\text { Microbiology }\end{array}$ \\
\hline Keyword: & $\begin{array}{l}\text { Escherichia coli, Sable Island horses, wildlife, antimicrobial resistance, } \\
\text { ESBL }\end{array}$ \\
\hline
\end{tabular}

\section{SCHOLARONE"}

Manuscripts 
A survey of the antimicrobial susceptibility of Escherichia coli isolated from Sable Island horses

ME Timonin ${ }^{1}, \mathrm{~J}_{\text {Poissant }}^{2,3}$, PD McLoughlin ${ }^{2}, \mathrm{CE}$ Hedlin ${ }^{1}$, Rubin $\mathrm{JE}^{1^{*}}$

${ }^{1}$ Department of Veterinary Microbiology and ${ }^{2}$ Department of Biology, University of

Saskatchewan, Saskatoon, Canada.

${ }^{3}$ College of Life and Environmental Sciences, University of Exeter, Cornwall Campus, Penryn, TR10 9FE, UK

*Corresponding Author

52 Campus Drive

Department of Veterinary Microbiology

Phone: (306) 966-7246

Fax: (306) 966-7244

Email: joe.rubin@usask.ca 


\begin{abstract}
The feral horses of Sable Island are a geographically isolated population located $\sim 160 \mathrm{~km}$ off the east coast of Nova Scotia, Canada. Because these horses have no contact with domestic animals, minimal contact with people and have never received antimicrobials, they offer a unique opportunity to study the dissemination of antimicrobial resistance in unmanaged populations. As part of an ongoing multi-disciplinary and individual-based monitoring program, we collected feces from 508 geolocalized horses ( $92 \%$ of the total population) between July and September 2014. We selectively cultured Escherichia coli on MacConkey and CHROMagar ESBL. Antimicrobial susceptibilities were determined and organisms resistant to $\beta$-lactam antimicrobials were screened for $\beta$-lactamase genes by PCR. E. coli was recovered from 146 (28.7\%) individuals and the majority of isolates (97\%) were susceptible to all drugs tested. Resistance to tetracycline was most common, including organisms isolated from 4 (2.7\%) of the colonized horses. A single isolate resistant to ampicillin, ceftriaxone and ceftiofur was identified which possessed the CTX-M-1 gene. Our findings demonstrate that although antimicrobial resistance is not common in this remote population, clinically relevant resistance genes are present.
\end{abstract}

Key words: Escherichia coli; Sable Island horses; wildlife; antimicrobial resistance; ESBL 
The dissemination of antimicrobial resistance is a complex process involving humans, domestic animals and wildlife. Escherichia coli is a common target in resistance surveillance studies due to its role as an indicator of resistance in Gram negative bacterial populations (OIE 2003). The emergence of antimicrobial resistance among Gram negative bacteria such as E. coli is recognized as a serious threat to the future of antimicrobial chemotherapy (WHO 2014). Among Gram negative bacteria hydrolytic enzymes called $\beta$-lactamases are the most common mechanism of resistance to the $\beta$-lactams; a large family of antimicrobials including the penicillins, cephalosporins and carbapenems (Rubin and Pitout 2014). The global emergence of resistance to the $3^{\text {rd }}$ generation cephalosporins, conferred by broad spectrum enzymes (the extended-spectrum $\beta$-lactamases (ESBL), and AmpC type $\beta$-lactamases) are particularly concerning because these drugs are critically important for treating a wide variety of infections in humans and animals (Nordmann et al. 2012; Pitout 2010).

Wildlife populations are ostensibly a reservoir of antimicrobial resistant organisms capable of maintaining, spreading and reintroducing resistant strains into human and domestic animal populations, although this remains largely unstudied (Greig et al. 2015). Studies examining drug resistance in bacteria from wildlife have identified wild birds as playing a role in the transmission of E. coli (for a review see (Guenther et al. 2011)). Many resistance surveillance investigations targeting wildlife examine either populations known to be in contact with a potential source of resistance genes or use more isolated populations to determine a baseline frequency of resistance in the absence of a commonly studied putative source (ex. hospitals, agricultural producers etc.) to determine the role of the human-wildlife interface in creating reservoir populations (Allen et al. 2010; Alroy and Ellis 2011; Guenther et al. 2010; Rwego et al. 
2008; Sjolund et al. 2008). In Canada, few studies describing the presence of antimicrobial resistant organisms in wildlife have been published. Two investigations conducted in Southern Ontario in 2007-8 targeting E. coli from raccoons and small rodents identified the broad spectrum CMY-2 type $\beta$-lactamase (Allen et al. 2011; Jardine et al. 2012). More recently, CTXM type ESBL producing E. coli have been isolated from Franklin Gulls in Manitoba, and American Crows in Saskatchewan (Bonnedahl et al. 2015; Parker et al. 2016). At present it is unknown whether these broad spectrum $\beta$-lactamases or other antimicrobial resistant organisms have infiltrated remote wildlife populations in Canada.

The feral horses of Sable Island National Park Reserve, Nova Scotia, comprise a unique, geographically isolated population that provides an opportunity to examine baseline levels of drug resistance. These feral horses inhabit an island located $160 \mathrm{~km}$ off the east coast of the province and have a long history of isolation (Christie 1980; Welsh 1975). The Sable Island horses have been protected from any human interference under Canadian law since the 1960's, and have not received modern veterinary care, including exposure to antimicrobials. In addition to very limited human presence on the island, the only animals that the horses are likely to interact with that might come into regular contact with humans are migratory seabirds or aquatic mammals such as grey seals. The horse population has been studied at the level of the individual by researchers at the University of Saskatchewan since 2007, with data on survival, reproduction, habitat selection, movement and dispersal patterns, body size and condition, associations, behaviour, life history, and pedigree collected yearly (e.g. (Contasti et al. 2012; Contasti et al. 2013; Debeffe et al. 2016; Marjamaki et al. 2013; van Beest et al. 2014). The objective of this investigation was to determine the baseline frequency of antimicrobial resistance in Sable Island 
horses by isolating and characterizing $E$. coli cultured from fecal samples of almost all individuals of this population.

Fecal samples from 508 of 552 (92\%) Sable Island horses alive in summer, 2014, were collected from July 22- September 7, as part of a multidisciplinary study examining the gastro-intestinal microbiota of the population. Freshly passed feces was collected from the ground after each horse was witnessed voiding, and were stored individually in a knotted nitrile glove for a maximum period of 7 hours before processing for freezing. Approximately $1 \mathrm{ml}$ of each fecal sample was transferred into a $2 \mathrm{ml}$ cryovial and then snap frozen in liquid nitrogen and maintained at $-196^{\circ} \mathrm{C}$ until received at the University of Saskatchewan, where they were immediately transferred to $-80^{\circ} \mathrm{C}$ for storage. The site where each sample was collected was mapped using GPS coordinates at the time of collection. Horses were broadly distributed across the island (Figure 1).

Upon return from the field and prior to processing, samples were thawed in small batches at room temperature for 20 minutes. We added approximately $1 \mathrm{ml}$ of sterile saline to each thawed sample which was then vortexed for $20-30$ seconds. A $10 \mu 1$ aliquot of the fecal suspension was plated onto on MacConkey (Becton, Dickinson and Company, Sparks, MD, United States) and CHROMagar ESBL (CHROMagar, Paris, France) agars using a calibrated loop for the selective culture of $E$. coli. We incubated media overnight at $35^{\circ} \mathrm{C}$, and identified isolates biochemically using the citrate, urea and indole tests (Winn et al. 2006). All isolates suspected to be E. coli based on colony morphology but with discordant biochemical test results (urease positive) were 
identified by phylogenetic analysis of the $16 \mathrm{~S}$ universal target (Dorsch and Stackebrandt 1992). Up to 3 isolates per horse were frozen at $-80^{\circ} \mathrm{C}$ in trypticase soy broth $+10 \%$ glycerol.

Antimicrobial minimum inhibitory concentrations for up to two isolates per horse were determined by broth micro-dilution using the Sensititre system (Trek Diagnostic Systems, Oakwood Village, Ohio, United States). Ampicillin (AMP), amoxicillin + clavulanate (AUG), cefoxitin (FOX), ceftiofur (XNL), ceftriaxone (AXO), tetracycline (TET), trimethoprim + sulfamethoxazole (SXT), sulfisoxazole (FIS), chloramphenicol (CHL), nalidixic acid (NAL), ciprofloxacin (CIP) and gentamicin (GEN) were included. Tests were done and interpreted in accordance with the Clinical and Laboratory Standards Institute (CLSI) guidelines and manufacturer's instructions (CLSI 2012, 2014, 2015). Isolates resistant to 3rd generation cephalosporins (ceftriaxone or ceftiofur) were screened for CTX-M type $\beta$-lactamases using previously published primers (Pitout et al. 2004). To identify the allele of any loci amplified, we sequenced PCR products. We used broth mating conjugation assays to assess the transferability of resistance in ESBL producing strains using the sodium azide resistant E. coli strain J53 as a plasmid recipient, and cefotaxime to select for ESBL harbouring transconjugants (Peirano et al. 2014).

Of the 508 horses sampled, $251 \mathrm{E}$. coli isolates were recovered from 146 horses $(28.7 \%)$, including 27 (18.5\%) carrying phenotypically atypical (urease positive) isolates. No E. coli were recovered from CHROMagar ESBL. This low recovery rate was unexpected as E. coli is a ubiquitous colonizer of the mammalian gut; in one study of equine feces E. coli was isolated from $98 \%$ of samples (Moriarty et al. 2015). This low recovery rate may be attributable to diet of 
these animals, differences in forage quality and the large volume of ingested sand may have altered the gut environment compared with domestic horses, resulting in differences in microbial communities (Willing et al. 2009). There is a distinct gradient in habitat quality, particularly in access to high quality forage, on Sable Island (Contasti et al. 2012), but E. coli was isolated from samples distributed across the island (Figure 2) in a similar pattern to the distribution of the horse population (Figure 1). Thus, at least on a broad scale, the pattern of E. coli distribution amongst the Sable Island horses does not appear to be linked to habitat or forage quality. Alternatively, the possibility of sample handling and storage conditions affecting the viability of $E$. coli cannot be ruled out. Although one investigation found that the recovery rate of $E$. coli from horse feces following storage at $-80^{\circ} \mathrm{C}$ with glycerol was actually significantly higher than from fresh samples, no cryoprotectant was added to the feces tested in our study (Masters et al. 2015).

The majority of $E$. coli isolates 244 (97\%) from 139 (95\%) horses, were susceptible to all antimicrobials tested (Table 1). Seven horses carried E. coli resistant to at least one antimicrobial; tetracycline resistance was most commonly identified including 4 isolates (1.6\%) from 4 horses (2.7\%) (Table 2). A single isolate resistant to ceftiofur and ceftriaxone was identified, and found to harbour the CTX-M-1 gene. By broth conjugation, we were able to demonstrate transmission of the phenotype and gene to the plasmid recipient strain E. coli J53. This finding is consistent with the hypotheses that the presence of resistance in wildlife is primarily a result of contact with humans influenced environments (Bonnedahl et al. 2008; Parker et al. 2016). 
Since the early 2000s the CTX-M type enzymes have been the predominant ESBLs identified in human infections and also seem to be increasingly encountered in animals (Pitout 2012; Rubin and Pitout 2014). CTX-M-1 is often associated with E. coli from poultry, although it has also been recovered from the environment, food, and people (Muller et al. 2016). Unlike the urban or agricultural environments from which resistant organisms are most commonly recovered, Sable Island ostensibly lacks the selective pressures for the development and maintenance of resistance. Previous studies have investigated antimicrobial resistant E. coli from wildlife in similarly remote areas which have minimal contact with humans or agriculture, including penguins in Antarctica (Bonnedahl et al. 2008; Guenther et al. 2010). A 2008 report describing resistant $E$. coli in birds in the high arctic speculated that resistance may have been carried from lower latitudes along migratory flyways (Sjolund et al. 2008). The low frequency of resistance found on Sable Island is consistent with or lower than previous reports describing resistance in $E$. coli $0 \%, 5.5 \%$ and 24\% in Antarctica, Rural Germany and the Azores respectively (Bonnedahl et al. 2008; Guenther et al. 2010; Santos et al. 2013). We suspect that the CTX-M-1 carrying E. coli was most likely brought Sable Island by a seabird, grey seal and contracted by the horse from subsequent environmental contamination. Human visitors to the island are another possible source of resistant organisms; an estimated 100-150 people may come to Sable Island annually for a variety of activities (e.g. research, work or recreation). Although no physical contact between people and horses is permitted, animals do frequent the area immediately surrounding the enclosures containing buildings, research equipment and high human use areas. .

In summary, we describe a low recovery rate of $E$. coli from Sable Island horses with a substantial number of biochemically atypical (urease producing) strains. The low rates of 
resistance identified will serve as a baseline for subsequent investigations targeting this population. We propose to use this population as a sentinel for identifying the dissemination of antimicrobial resistance into remote ecosystems.

\section{Acknowledgments}

The authors would like to thank the numerous students and volunteers who have contributed to the Sable Island horse project and assisted with sample collection. This project was supported by in-kind and logistical support from Parks Canada Agency, and funding from the L. David Dubé and Heather Ryan Veterinary Health and Research fund, an operating grant to PDM from the Natural Sciences and Engineering Research Council, and the Canada Foundation for Innovation. Additional in-kind support was provided by Fisheries and Oceans Canada, and travel and shipping provided by Sable Aviation. MET was supported by the Interprovincial Undergraduate Student Research program. JP is supported by a Leverhulme Trust Early Career Fellowship.

\section{References Cited}


Allen, H.K., Donato, J., Wang, H.H., Cloud-Hansen, K.A., Davies, J., and Handelsman, J. 2010. Call of the wild: antibiotic resistance genes in natural environments. Nat Rev Microbiol 8(4): 251-259. doi: 10.1038/nrmicro2312.

Allen, S.E., Boerlin, P., Janecko, N., Lumsden, J.S., Barker, I.K., Pearl, D.L., Reid-Smith, R.J., and Jardine, C. 2011. Antimicrobial resistance in generic Escherichia coli isolates from wild small mammals living in swine farm, residential, landfill, and natural environments in southern Ontario, Canada. Appl Environ Microbiol 77(3): 882-888. doi: 10.1128/AEM.01111-10.

Alroy, K., and Ellis, J.C. 2011. Pilot study of antimicrobial-resistant Escherichia coli in herring gulls (Larus argentatus) and wastewater in the northeastern United States. J Zoo Wildl Med 42(1): 160-163. doi: 10.1638/2010-0130.1.

Bonnedahl, J., Olsen, B., Waldenstrom, J., Broman, T., Jalava, J., Huovinen, P., and Osterblad, M. 2008. Antibiotic susceptibility of faecal bacteria in Antarctic penguins. Polar Biol 31(6): 759-763. doi: 10.1007/s00300-008-0430-3.

Bonnedahl, J., Stedt, J., Waldenstrom, J., Svensson, L., Drobni, M., and Olsen, B. 2015. Comparison of Extended-Spectrum beta-Lactamase (ESBL) CTX-M Genotypes in Franklin Gulls from Canada and Chile. PLoS One 10(10): e0141315. doi: 10.1371/journal.pone.0141315.

Christie, B.J. 1980. Horses of Sable Island. Petheric Press, Halifax, Canada.

CLSI. 2012. M07-A9 Methods for dilution antimicrobial susceptibility tests for bacteria that grow aerobically; approved standard - ninth edition. Clinical and Laboratory Standards Institute.

CLSI. 2014. M100-S24 Performance standards for antimicrobial susceptibility testing; twenty-fourth informational supplement. Clinical and Laboratory Standards Institute.

CLSI. 2015. VET01S Performance standards for antimicrobial disk and dilution susceptibility tests for bacteria isolated from animals. Clinical and Laboratory Standards Institute. 
Contasti, A.L., Tissier, E.J., Johnstone, J.F., and McLoughlin, P.D. 2012. Explaining spatial heterogeneity in population dynamics and genetics from spatial variation in resources for a large herbivore. PLoS One 7(10): e47858. doi: 10.1371/journal.pone.0047858.

Contasti, A.L., Van Beest, F.M., Vander Wal, E., and Mcloughlin, P.D. 2013. Identifying Hidden Sinks in Growing Populations From Individual Fates and Movements: The Feral Horses of Sable Island. J Wildlife Manage 77(8): 1545-1552. doi: 10.1002/jwmg.625.

Debeffe, L., McLoughlin, P.D., Medill, S.A., Stewart, K., Andres, D., Shury, T., Wagner, B., Jenkins, E., Gilleard, J.S., and Poissant, J. 2016. Negative covariance between parasite load and body condition in a population of feral horses. Parasitology 143(8): 983-997. doi: 10.1017/S0031182016000408.

Dorsch, M., and Stackebrandt, D. 1992. Some modifications in the procedure of direct sequencing of PCR amplified 16S rDNA. Journal of Microbiological Methods 16: 271-279.

Greig, J., Rajic, A., Young, I., Mascarenhas, M., Waddell, L., and LeJeune, J. 2015. A scoping review of the role of wildlife in the transmission of bacterial pathogens and antimicrobial resistance to the food Chain. Zoonoses Public Health 62(4): 269-284. doi: 10.1111/zph.12147.

Guenther, S., Ewers, C., and Wieler, L.H. 2011. Extended-Spectrum Beta-Lactamases Producing E. coli in Wildlife, yet Another Form of Environmental Pollution? Front Microbiol 2: 246. doi:

10.3389/fmicb.2011.00246.

Guenther, S., Grobbel, M., Heidemanns, K., Schlegel, M., Ulrich, R.G., Ewers, C., and Wieler, L.H. 2010. First insights into antimicrobial resistance among faecal Escherichia coli isolates from small wild mammals in rural areas. Sci Total Environ 408(17): 3519-3522. doi: 10.1016/j.scitotenv.2010.05.005. Jardine, C.M., Janecko, N., Allan, M., Boerlin, P., Chalmers, G., Kozak, G., McEwen, S.A., and Reid-Smith, R.J. 2012. Antimicrobial resistance in Escherichia coli isolates from raccoons (Procyon lotor) in Southern Ontario, Canada. Appl Environ Microbiol 78(11): 3873-3879. doi: 10.1128/AEM.00705-12. 
Marjamaki, P.H., Contasti, A.L., Coulson, T.N., and McLoughlin, P.D. 2013. Local density and group size interacts with age and sex to determine direction and rate of social dispersal in a polygynous mammal. Ecol Evol 3(9): 3073-3082. doi: 10.1002/ece3.694.

Masters, N., Christie, M., Stratton, H., and Katouli, M. 2015. Viability and stability of Escherichia coli and enterococci populations in fecal samples upon freezing. Can J Microbiol 61(7): 495-501. doi:

10.1139/cjm-2015-0020.

Moriarty, E.M., Downing, M., Bellamy, J., and Gilpin, B.J. 2015. Concentrations of faecal coliforms, Escherichia coli, enterococci and Campylobacter spp. in equine faeces. N Z Vet J 63(2): 104-109. doi: 10.1080/00480169.2014.952789.

Muller, A., Stephan, R., and Nuesch-Inderbinen, M. 2016. Distribution of virulence factors in ESBLproducing Escherichia coli isolated from the environment, livestock, food and humans. Sci Total Environ 541: 667-672. doi: 10.1016/j.scitotenv.2015.09.135.

Nordmann, P., Dortet, L., and Poirel, L. 2012. Carbapenem resistance in Enterobacteriaceae: here is the storm! Trends Mol Med 18(5): 263-272. doi: 10.1016/j.molmed.2012.03.003.

OIE. 2003. Terrestrial Animal Health Code Guidelines for the harmonisation of antimicrobial resistance surveillance and monitoring programs. In OIE International Standards on Antimicrobial Resistance. OIE (World Organization for Animal Health), Paris, France. pp. 5-27.

Parker, D., Sniatynski, M.I., Mandrusiak, D., and Rubin, J.E. 2016. Extended-spectrum beta-lactamase producing Escherichia coli isolated from wild birds in Saskatoon, Canada. Lett Appl Microbiol 63(1): 1115. doi: 10.1111/lam.12589.

Peirano, G., Ahmed-Bentley, J., Fuller, J., Rubin, J.E., and Pitout, J.D. 2014. Travel-related carbapenemase-producing Gram-negative bacteria in Alberta, Canada: the first 3 years. J Clin Microbiol 52(5): 1575-1581. doi: JCM.00162-14 [pii]

10.1128/JCM.00162-14. 
Pitout, J.D. 2010. Infections with extended-spectrum beta-lactamase-producing Enterobacteriaceae: changing epidemiology and drug treatment choices. Drugs 70(3): 313-333. doi: 5 [pii]

10.2165/11533040-000000000-00000.

Pitout, J.D. 2012. Extraintestinal pathogenic Escherichia coli: an update on antimicrobial resistance, laboratory diagnosis and treatment. Expert Rev Anti Infect Ther 10(10): 1165-1176. doi:

10.1586/eri.12.110.

Pitout, J.D., Hossain, A., and Hanson, N.D. 2004. Phenotypic and molecular detection of CTX-M-betalactamases produced by Escherichia coli and Klebsiella spp. J Clin Microbiol 42(12): 5715-5721. doi: 42/12/5715 [pii]

10.1128/JCM.42.12.5715-5721.2004.

Rubin, J.E., and Pitout, J.D.D. 2014. Extended-spectrum $\beta$-lactamase, carbapenemase and AmpC producing Enterobacteriaceae in companion animals. Vet Microbiol. doi:

http://dx.doi.org/10.1016/j.vetmic.2014.01.017.

Rwego, I.B., Gillespie, T.R., Isabirye-Basuta, G., and Goldberg, T.L. 2008. High rates of Escherichia coli transmission between livestock and humans in rural Uganda. J Clin Microbiol 46(10): 3187-3191. doi: 10.1128/JCM.00285-08.

Santos, T., Silva, N., Igrejas, G., Rodrigues, P., Micael, J., Rodrigues, T., Resendes, R., Goncalves, A., Marinho, C., Goncalves, D., Cunha, R., and Poeta, P. 2013. Dissemination of antibiotic resistant Enterococcus spp. and Escherichia coli from wild birds of Azores Archipelago. Anaerobe 24: 25-31. doi: 10.1016/j.anaerobe.2013.09.004.

Sjolund, M., Bonnedahl, J., Hernandez, J., Bengtsson, S., Cederbrant, G., Pinhassi, J., Kahlmeter, G., and Olsen, B. 2008. Dissemination of multidrug-resistant bacteria into the Arctic. Emerg Infect Dis 14(1): 7072. doi: 10.3201/eid1401.070704. 
van Beest, F.M., Uzal, A., Vander Wal, E., Laforge, M.P., Contasti, A.L., Colville, D., and McLoughlin, P.D. 2014. Increasing density leads to generalization in both coarse-grained habitat selection and finegrained resource selection in a large mammal. J Anim Ecol 83(1): 147-156. doi: 10.1111/13652656.12115.

Welsh, D.A. 1975. Population, behavioural and grazing ecology of the horses of Sable Island. Dalhousie University

WHO. 2014. Antimicrobial Resistance: global report on surveillance. World Health Organization.

Willing, B., Voros, A., Roos, S., Jones, C., Jansson, A., and Lindberg, J.E. 2009. Changes in faecal bacteria associated with concentrate and forage-only diets fed to horses in training. Equine Vet J 41(9): 908-914. Winn, W., Allen, S., Janda, W., Koneman, E., Procop, G., Schreckenberger, P., and Woods, G. 2006. The Enterobacteriaceae. In Koneman's Color Atlas and Textbook of Diagnostic Microbiology. Edited by W. Winn and S. Allen and W. Janda and E. Koneman and G. Procop and P. Schreckenberger and G. Woods. Lippincott Williams \& Wilkins, Baltimore, MD. pp. 211-302. 
Title: Table 1: Susceptibility profiles for E. coli isolates $(n=251)$ cultured from 146 Sable Island horse fecal samples

Footnote: Abbreviations: AMP - ampicillin, AUG - amoxicillin + clavulanate, AXO - ceftriaxone, XNL ceftiofur, FOX - cefoxitin, TET - tetracycline, SXT - trimethoprim + sulfamethoxazole, FIS -sulfisoxizole

Title: Table 2. Minimum inhibitory concentration distribution of $E$. coli $(n=251)$ isolated from Sable Island Horses $(n=146)$.

Footnote: Antimicrobial minimum inhibitory concentration (MIC) distribution for $E$. coli isolates ( $n=113$ ) for ampicillin (AMP), ceftiofur (XNL), ceftriaxone (AXO), amoxicillin + clavulanic acid 2:1 (AUG), cefoxitin (FOX), tetracycline (TET), chloramphenicol ( $\mathrm{CHL})$, sulfisoxazole (FIS), trimethoprim + sulfamethoxazole 1:19 (SXT), gentamicin (GEN), nalidixic acid (NAL) and ciprofloxacin (CIP). \%R Isolates - percentage of isolates which were resistant; \#(\%)R Animals - number (percentage) of animals from which an isolate resistant to each drug was isolated. Cells corresponding to concentrations tested are white and resistance breakpoints are denoted by dark bars. The number of isolates inhibited at each concentration 
are noted in each cell, isolates not inhibited by the highest concentration of each drug are enumerated in the first concentration above the highest concentration tested.

Title: Figure 1. The location of Sable Island off the east coast of Nova Scotia with the location of horses sampled.

Title: Figure 2. The geographic collection site of E. coli positive fecal samples ( $n=146)$ on Sable Island. Footnote: Red squares represent $E$. coli resistant to antimicrobials $(n=7)$ and blue circles represent pansusceptible $E$. coli ( $n=137)$. Geolocation data was not available for 2 pan susceptible isolates. 


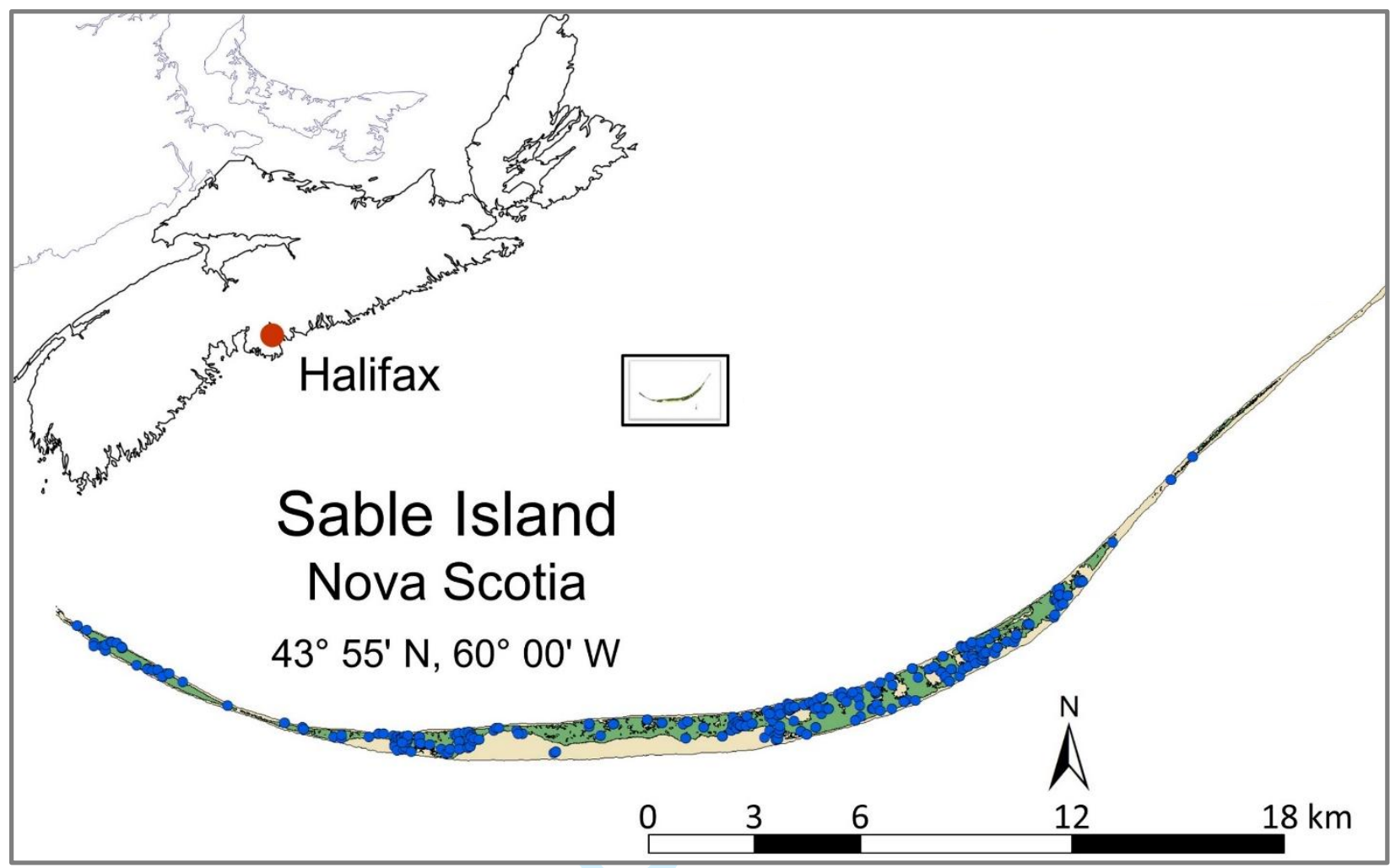


- Pan-susceptible E. coli $(n=137)$

- Resistant E. coli $(n=7)$

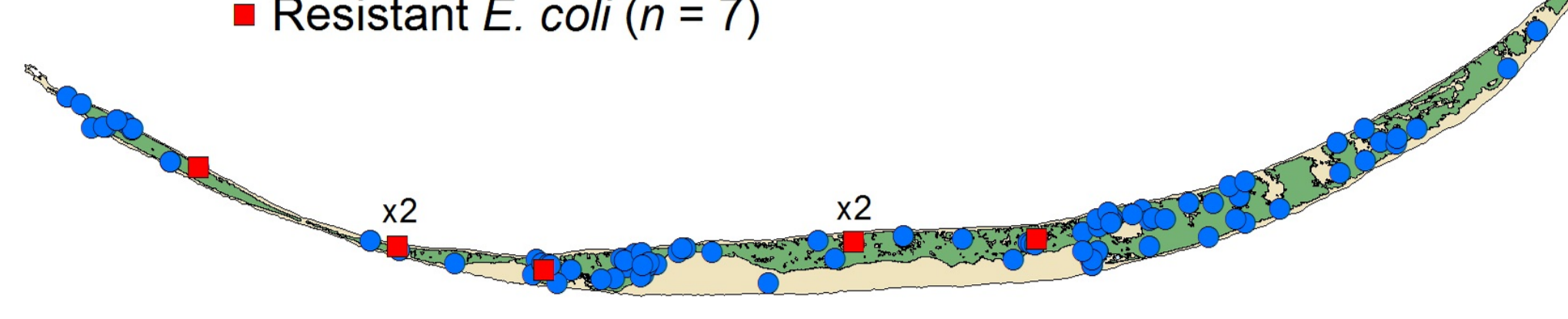




\begin{tabular}{llll}
\hline Phenotype & $\begin{array}{l}\text { Number }(\%) \\
\text { isolates }(\mathrm{n}=251)\end{array}$ & $\begin{array}{l}\text { Number }(\%) \\
\text { horses }(\mathrm{n}=146)\end{array}$ & $\begin{array}{l}\beta \text {-lactamase } \\
\text { gene } \\
\text { identified }\end{array}$ \\
\hline Pan-Susceptible & $244(97)$ & $139(95)$ & \\
AMP & $1(0.4)$ & $1(0.7)$ & \\
TET & $4(1.6)$ & $4(2.7)$ & \\
$*$ AMP + AUG + FOX & $1(0.4)$ & $1(0.7)$ & CTX-M-1 \\
*AMP + AXO + XNL + FIS + SXT & $1(0.4)$ & $1(0.7)$ & C \\
\hline
\end{tabular}




\begin{tabular}{|c|c|c|c|c|c|c|c|c|c|c|c|c|c|c|c|c|c|c|}
\hline Drug & 0.015 & 0.03 & 0.06 & 0.12 & 0.25 & 0.5 & 1 & 2 & 4 & 8 & 16 & 32 & 64 & 128 & 256 & 512 & $\begin{array}{c}\% \mathbf{R} \\
\text { Isolates } \\
\end{array}$ & $\begin{array}{l}\#(\%) R \\
\text { Animals } \\
\end{array}$ \\
\hline AMP & & & & & & & & 82 & 161 & 4 & 1 & & 3 & & & & $1.2 \%$ & $3(2.1 \%)$ \\
\hline XNL & & & & & 32 & 217 & 1 & & & & 1 & & & & & & $0.4 \%$ & $1(0.7 \%)$ \\
\hline AXO & & & & & 250 & & & & & & & & 1 & & & & $0.4 \%$ & $1(0.7 \%)$ \\
\hline AUG & & & & & & & & 13 & 187 & 50 & & 1 & & & & & $0.4 \%$ & $1(0.7 \%)$ \\
\hline FOX & & & & & & & & 15 & 192 & 41 & 2 & & 1 & & & & $0.4 \%$ & $1(0.7 \%)$ \\
\hline TET & & & & & & & & & 247 & & & & 4 & & & & $1.6 \%$ & $4(2.7 \%)$ \\
\hline CHL & & & & & & & & & 4 & 235 & 12 & & & & & & & \\
\hline FIS & & & & & & & & & & & 19 & 120 & 93 & 18 & & 1 & $0.4 \%$ & $1(0.7 \%)$ \\
\hline SXT & & & & 247 & & 1 & 2 & & & 1 & & & & & & & $0.4 \%$ & $1(0.7 \%)$ \\
\hline GEN & & & & & & 39 & 191 & 18 & 3 & & & & & & & & & \\
\hline NAL & & & & & & & 8 & 166 & 77 & & & & & & & & & \\
\hline CIP & 243 & 8 & & & & & & & & & & & & & & & & \\
\hline
\end{tabular}

